\title{
Review Article \\ Effect of Aerobic Exercise Training on Blood Pressure in Indians: Systematic Review
}

\author{
Sonu Punia, ${ }^{1}$ Sivachidambaram Kulandaivelan, ${ }^{1}$ Varun Singh, ${ }^{1}$ and Vandana Punia ${ }^{2}$ \\ ${ }^{1}$ Department of Physiotherapy, GJUST, Hisar 125001, India \\ ${ }^{2}$ Human Resource Development Center, GJUST, Hisar 125001, India \\ Correspondence should be addressed to Sivachidambaram Kulandaivelan; tryhard2024@yahoo.co.in
}

Received 23 April 2016; Revised 6 June 2016; Accepted 19 June 2016

Academic Editor: Tadeusz Robak

Copyright (C) 2016 Sonu Punia et al. This is an open access article distributed under the Creative Commons Attribution License, which permits unrestricted use, distribution, and reproduction in any medium, provided the original work is properly cited.

\begin{abstract}
Introduction. High blood pressure (BP) is one of the most important modifiable risk factors for cardiovascular diseases, which accounts for one in every eight deaths worldwide. It has been predicted that, by 2020 , there would be $111 \%$ increase in cardiovascular deaths in India. Aerobic exercise in the form of brisk walking, jogging, running, and cycling would result in reduction in BP. Many meta-analytical studies from western world confirm this. However, there is no such review from Indian subcontinent. Objective. Our objective is to systematically review and report the articles from India in aerobic exercise on blood pressure. Methodology. Study was done in March 2016 in Google Scholar using search terms "Aerobic exercise" AND "Training" AND "Blood pressure" AND "India." This search produced 3210 titles. Results. 24 articles were identified for this review based on inclusion and exclusion criteria. Total of 1107 subjects participated with median of 25 subjects. Studies vary in duration from +3 weeks to 12 months with each session lasting 15-60 minutes and frequency varies from 3 to 8 times/week. The results suggest that there was mean reduction of $-05.00 \mathrm{mmHg}$ in SBP and $-03.09 \mathrm{mmHg}$ in DBP after aerobic training. Conclusion. Aerobic training reduces the blood pressure in Indians.
\end{abstract}

\section{Introduction}

Elevated blood pressure, also known as hypertension, is one of the most important modifiable risk factors for cardiovascular disease and is accounting for $10 \%$ of overall deaths in India [1]. In a meta-analysis of 142 studies from rural and urban populations of India, it was concluded that hypertension is emerging as a major health problem in India [2] and is more in urban than in rural subjects [3] and is associated with a higher risk of developing coronary heart disease (CHD), congestive heart failure, and stroke $[4,5]$.

Aerobic exercises are advised for health promotion and prophylaxis for many cardiovascular diseases. They refer to all exercises that involve major muscle groups and improve oxygen consumption by the body. Many methods of aerobic exercise are available like walking, jogging, running, cycling, and others. Recent meta-analytical study from western world confirms that aerobic exercise would result in clinically significant reduction in blood pressure [6]. Aerobic exercise such as walking not only improves fitness but also improves overall quality of life and decreases all-cause mortality [7, 8].

Even though it is confirmed from western world that exercises are helpful, there is little available evidence from India. Many of Indian literatures are grey in nature, that is, short studies done for postdoctoral dissertation or doctoral thesis which are not available in standard electronic database, namely, Pubmed, CINHAL, and EMBASE. However, recent rise in electronic journals with or without print copy encourages young researchers from India to publish their research in them. But these journals are not indexed in major databases and hence are not noticed and reported by other authors. Thus the objective of this paper is to collect the available literature from India using secondary search engine "Google Scholar" and derive the conclusion whether aerobic exercise is reducing blood pressure in normal and pathological conditions or not in Indians. 


\section{Methodology}

Computerized literature search was performed using "Google Scholar" search engine during March 2016. Keywords or search protocol used for this review is "Aerobic Exercise" AND “Training” AND “Blood Pressure” AND “India.” Inclusion criteria for this review were as follows: (i) experimental study with post-premeasurement of BP, (ii) aerobic exercise as the exercise intervention with minimal duration of 3 weeks, (iii) full-text articles in English published in journals with ISSN number, (iv) study done in any part of India without any time limitation, and (v) subjects being either normal or with following clinical conditions: obesity, hypertension, and diabetes. A main exclusion criterion was other clinical conditions ( 2 articles were excluded based on this criterion). Search protocol resulted in 3210 articles. Authors Sonu Punia and Sivachidambaram Kulandaivelan reviewed 3210 titles individually and selected articles based on inclusion and exclusion criteria. Sonu Punia selected 19 articles and Sivachidambaram Kulandaivelan selected 24 articles. Authors Vandana Punia and Varun Singh studied 43 articles and selected 25 articles (18 were duplicates). Results were prepared by Varun Singh. During this, we found two articles which used the same results in their papers $[9,10]$. Recent one was excluded from the review [9].

Mean difference with 95\% CI (confidence interval) for individual studies was calculated using mean, standard deviation (SD), and sample size (this was not possible in [11-15] due to nonavailability of SD). If there are 2 or more groups in an article [12, 15-17], standard mean of all groups BP values was used as single measure. Subtotal and overall reduction in SBP and DBP were calculated by adding individual BP values divided by number of studies ([18] was excluded from analysis due to this criterion). Mean difference with 95\% CI was calculated using standard formula as described earlier.

\section{Results}

We selected 24 articles [10-33] with 1107 subjects (mean: 46; median: 25) for this review. Even though we did not use any time limits, all articles included in this reviews were from 2009 to 2015 . Out of 24 articles, 13 articles [10-13, 16, 19-26] used healthy subjects and 11 articles $[14,15,17,18,27-33]$ used clinical condition subjects with hypertension [14, 18, 27, 28] and diabetes [15, 17, 29-33]. Aerobic exercise was performed for the mean period of 40 minutes (median: 30) with a frequency of 4.8 days.week ${ }^{-1}$ (median: 5) and total duration of 12.5 weeks (median: 12) (Table 1 ).

A total of 5 articles [11,16, 19-21] were included in young healthy adults population with total of 165 participants (mean: 33; median: 15; males/females: 73/92). The number of sessions in a week ranged from 3 to 8 sessions (mean: 5; median: 4). Total duration of program ranged from 4 to 16 weeks (mean: 11.2; median: 12.0). A total of 6 articles $[12,13,22-25]$ were included in healthy middle and old age population with total of 541 participants (mean: 90; median: 25). Four articles mentioned the duration of session which ranged from 15 minutes to 45 minutes (mean: 35; median: 30). The number of sessions in a week ranged from 3 to 6 sessions (mean: 4.7; median: 5). Total duration of program ranged from 3 to 16 weeks (mean: 9; median: 11). A total of 2 articles $[10,26]$ were included in obese adults population with total of 40 participants (mean: 20; male/female: 30/10) (Table 1).

A total of 4 articles $[14,18,27,28]$ were included in aerobic exercise in hypertensive patients population with total of 122 participants (mean: 30.5; median: 28.5). Duration of exercise in single session ranged from 30 minutes to 60 minutes (mean: 40; median: 40). Frequency of exercise per week ranged from 3 to 5 days (mean: 4; median: 4). Total duration of exercise program ranged from 6 to 8 weeks (mean: 6.5; median: 6). A total of 7 articles $[15,17,29-33]$ were included in aerobic exercise in diabetic patients population with total of 239 participants (mean: 34; median: 24). Duration of single session ranged from 15 minutes to 45 minutes (mean: 34; median: 30). Frequency of exercise per week ranged from 3 days to 7 days (mean: 5.3; median: 6). Total duration of the program ranged from 7 weeks to 52 weeks (mean: 21 ; median: 16) (Table 1).

Table 2 shows the effect of aerobic training of 3 weeks or more on blood pressure in individual studies basis. The results are classified into healthy adults and other clinical conditions, that is, hypertension and diabetes.

Figure 1 shows summary of aerobic training on SBP in Indians. There is a mean reduction of $3.71 \mathrm{mmHg}(95 \%$ CI: -2.74 to -4.68$)$ in healthy Indians, $5.38 \mathrm{mmHg}(95 \%$ CI: -2.99 to -7.77$)$ in hypertensive Indians, and $7.24 \mathrm{mmHg}$ (95\% CI: -5.89 to -8.59 ) in diabetic Indians. Overall, aerobic training with mean duration of 12.5 weeks reduced SBP to $05.00 \mathrm{mmHg}$ (95\% CI: -4.18 to -5.82$)$ in Indians.

Figure 2 shows summary of aerobic training on DBP in Indians. There is a mean reduction of $2.79 \mathrm{mmHg}(95 \% \mathrm{CI}$ : -2.12 to -3.46$)$ in healthy Indians, $3.66 \mathrm{mmHg}$ (95\% CI: -2.02 to -5.30$)$ in hypertensive Indians, and 3.41 (95\% CI: -2.61 to -4.21 ) in diabetic Indians. Overall, aerobic training with mean single session duration of 40 minutes reduced DBP to $3.09 \mathrm{mmHg}$ (95\% CI: -2.57 to -3.61$)$ in Indians.

Out of 24 included articles (23 for meta-analysis), 10 studies used control group (5 healthy subjects and 5 subjects with clinical condition) $[10,12,14,17,23,24,26,30$, 32, 33]. Subgroup analysis of control versus experimental group in healthy Indian subjects showed mean reduction of $2.92 \mathrm{mmHg}$ in SBP and $2.25 \mathrm{mmHg}$ in $\mathrm{DBP}$ in favor of experimental group. The same analysis in clinical condition showed mean reduction of $5.4 \mathrm{mmHg}$ in SBP and $2.6 \mathrm{mmHg}$ in DBP in favor of experimental group.

\section{Discussion}

Primary objective of this review is to collect and present the literature from India of aerobic exercise on blood pressure. We found 24 articles from different parts of India (north, 5, south, 10, east, 3, and west, 6). Results show $5.00 \mathrm{mmHg}$ reduction in SBP and $3.09 \mathrm{mmHg}$ reduction in DBP. This result is supported by several meta-analyses from western population [6, 34-36]. Cornelissen and Smart [6] studied the effect of aerobic exercise on blood pressure in 105 study groups (93 RCTs) with 3500 subjects. Their results showed 
TABLE 1: Basic characteristics of included studies.

\begin{tabular}{|c|c|c|c|c|c|}
\hline Author et al., year & $\begin{array}{c}\text { Population } \\
\text { (male/female) }\end{array}$ & Intensity & $\begin{array}{c}\text { Session } \\
\text { duration }\end{array}$ & Frequency & Total duration \\
\hline \multicolumn{6}{|c|}{ Healthy young adults $(n=165)$} \\
\hline Dureja and Bardhan, 2014 [19] & $05(05 / 00)$ & $7-10 \mathrm{Km} / \mathrm{hr}$ & $15-25$ minutes & 6 days/week & 4 weeks \\
\hline Munieskhar et al., 2014 [20] & $50(00 / 50)$ & NA & 30 minutes & 7 days/week & 12 weeks \\
\hline Golda and Margaret, 2013 [11] & $10(10 / 00)$ & $65-80 \%$ HRR & 90 minutes & 3 days/week & 12 weeks \\
\hline Harsoda and Purohit, 2013 [21] & $15(15 / 00)$ & $10 \mathrm{Km} / \mathrm{hr}$ & 30 minutes & 5 days/week & 12 weeks \\
\hline Hulke et al., 2012 [16] & $85(43 / 42)$ & RPE & 60 minutes & 8 sessions/week & 16 weeks \\
\hline \multicolumn{6}{|c|}{ Middle and old age $(n=541)$} \\
\hline $\begin{array}{l}\text { Karadkhedkar and Somwanshi, } \\
2015 \text { [22] }\end{array}$ & $30(00 / 30)$ & $60-75 \% \mathrm{HR}_{\max }$ & 30 minutes & 5 days/week & 16 weeks \\
\hline Selvakumar and Raja, 2015 [12] & 20 & NA & NA & 5 days/week & 12 weeks \\
\hline Singh et al., 2015 [23] & $17(06 / 11)$ & $\begin{array}{l}50-75 \% \\
\text { APMHR }\end{array}$ & 30 minutes & 5 days/week & 3 weeks \\
\hline Raja, 2014 [24] & 15 & NA & NA & 6 days/week & 13 weeks \\
\hline Subitha et al., 2012 [25] & $38(18 / 20)$ & NA & 15 minutes & 3 days/week & 10 weeks \\
\hline Lakshminarayanan et al., 2012 [13] & 421 & Brisk & 30 minutes & 4 days/week & 10 weeks \\
\hline \multicolumn{6}{|c|}{ Obese adults $(n=40)$} \\
\hline Chaudhary et al., 2010 [10] & $10(00 / 10)$ & $60-70 \%$ MHR & Till exhaustion & 3 days/week & 6 weeks \\
\hline Raju, 2014 [26] & $30(30 / 00)$ & Varying & 60 minutes & 6 days/week & 12 weeks \\
\hline \multicolumn{6}{|c|}{ Hypertensive adults $(n=122)$} \\
\hline Jaiswal et al., 2015 [27] & 15 & $50-80 \%$ HRR & 30 minutes & 5 days/week & 6 weeks \\
\hline Patel and Desai, 2014 [18] & $30(21 / 09)$ & NA & 30 minutes & NA & 6 weeks \\
\hline Bose and Dhanalakshmi, 2012 [28] & 50 & $60-75 \% \mathrm{HR}_{\max }$ & 50 minutes & 3 days/week & 6 weeks \\
\hline Saptharishi et al., 2009 [14] & $27(19 / 08)$ & Brisk & $50-60$ minutes & 4 days/week & 8 weeks \\
\hline \multicolumn{6}{|c|}{ Diabetic adults $(n=239)$} \\
\hline Sadhesh and Kumar, 2014 [15] & 15 & NA & 45 minutes & 7 days/week & 7 weeks \\
\hline Ghosh and Roy, 2013 [29] & $24(00 / 24)$ & $\begin{array}{l}65-75 \% \\
\text { run/walk }\end{array}$ & 15 minutes & 6 days/week & 25 weeks \\
\hline Sanghani et al., 2013 [30] & 74 & Varying & 45 minutes & 6 days/week & 26 weeks \\
\hline Tiwari et al., 2012 [17] & $51(28 / 23)$ & NA & 30 minutes & NA & 12 weeks \\
\hline Sridhar et al., 2010 [31] & $55(30 / 25)$ & NA & 45 minutes & 7 days/week & 52 weeks \\
\hline Arora et al., 2009 [32] & $10(06 / 04)$ & NA & 30 minutes & 3 days/week & 8 weeks \\
\hline Shenoy et al., 2009 [33] & $10(06 / 04)$ & NA & 30 minutes & 3 days/week & 16 weeks \\
\hline
\end{tabular}

APHRM, age predicted heart rate maximum; $\mathrm{HR}_{\max }$, heart rate maximum; HRR, heart rate reserve; $\mathrm{MHR}$, maximal heart rate; $\mathrm{NA}$, not available; $\mathrm{RPE}$, ratings of perceived exertion.

mean difference (MD) of $-3.5 \mathrm{mmHg}$ in SBP and $-2.5 \mathrm{mmHg}$ in DBP. Whelton et al. [35] studied effect of aerobic exercise on blood pressure in 53 RCTs (2419 subjects). They found MD of $-3.84 \mathrm{mmHg}$ in SBP $(-4.97$ to -2.72$)$ and $-2.58 \mathrm{mmHg}$ in DBP ( -3.35 to -1.81$)$. Halbert et al. [36] analyzed 26 RCTs of at least 4-week aerobic training on blood pressure. Their results are similar to our findings (SBP, $-04.70 \mathrm{mmHg}$, and DBP, $-03.10 \mathrm{mmHg}$ ). All the three meta-analyses included here used either normotensive or hypertensive subjects only; diabetes was not reported in these meta-analyses. So we did another subanalysis for healthy and hypertensive studies which showed mean reduction of $4.03 \mathrm{mmHg}$ (95\% CI: -3.05 to -5.01$)$ in SBP and of $2.96 \mathrm{mmHg}$ (95\% CI: -2.29 to -3.63$)$ in DBP.

As compared to control group, aerobic training reduced $4.16 \mathrm{mmHg}$ in SBP and $2.43 \mathrm{mmHg}$ in DBP in experimental group of Indians which is lower end of 95\% CI in postpremean MD of present study. This is in agreement with western meta-analysis $[6,35,36]$. We compared individual studies' SBP MD (95\% CI) with overall meta-analysis' SBP mean (Figure 1) and results showed that 16 of 23 studies are in agreement with meta-analysis' SBP mean. Three articles (2 healthy subjects $[16,22]$ and 1 diabetic subject [31]) only deviated from meta-analysis' SBP mean. 17 of 23 studies' DBP MD (95\% CI) are in agreement with meta-analysis' DBP mean (Figure 2). Two articles (both of diabetic population [29, 31]) only deviated from meta-analysis' DBP mean. This suggests that all articles' results are reliable to each other. The mean reduction of $\mathrm{BP}$ in all the three western meta-analyses $[6,35$, 36 ] is within $95 \%$ CI of present meta-analysis; hence, we could predict that future studies from India will reproduce the same reduction after aerobic training. 
TABLE 2: Effect of aerobic exercise training on blood pressure in Indians.

\begin{tabular}{|c|c|c|c|c|c|}
\hline Author et al., year & Before SBP & After SBP & Before DBP & After DBP & $\begin{array}{c}\text { Mean difference } \\
(\mathrm{MD})\end{array}$ \\
\hline \multicolumn{6}{|c|}{ Healthy young adults $(n=165)$} \\
\hline Dureja and Bardhan, 2014 [19] & $116.00 \pm 5.47$ & $110.00 \pm 6.07$ & $79.00 \pm 8.94$ & $69.00 \pm 7.41$ & $\begin{array}{l}\text { SBP }-06.00 \\
\text { DBP }-10.00\end{array}$ \\
\hline Munieskhar et al., 2014 [20] & $99.6 \pm 8.38$ & $95.1 \pm 6.9$ & $66.2 \pm 5.67$ & $62.15 \pm 3.43$ & $\begin{array}{l}\text { SBP }-04.50 \\
\mathrm{DBP}-04.05\end{array}$ \\
\hline Golda and Margaret, 2013 [11] & 128.5 & 121.7 & 80.52 & 78.27 & $\begin{array}{l}\text { SBP }-06.80 \\
\mathrm{DBP}-02.25\end{array}$ \\
\hline Harsoda and Purohit, 2013 [21] & $120.2 \pm 7.55$ & $112.2 \pm 6.88$ & $78.4 \pm 8.01$ & $75.6 \pm 6.73$ & $\begin{array}{l}\text { SBP }-08.00 \\
\text { DBP }-02.80\end{array}$ \\
\hline Hulke et al., 2012 [16] & $113.74 \pm 8.36$ & $112.36 \pm 6.16$ & $73.72 \pm 8.4$ & $72.29 \pm 6.56$ & $\begin{array}{l}\text { SBP }-01.38 \\
\text { DBP }-01.43\end{array}$ \\
\hline \multicolumn{6}{|c|}{ Middle and old age $(n=541)$} \\
\hline $\begin{array}{l}\text { Karadkhedkar and Somwanshi, } \\
2015 \text { [22] }\end{array}$ & $126.46 \pm 6.30$ & $124.39 \pm 1.86$ & $86.03 \pm 7.12$ & $83.60 \pm 7.57$ & $\begin{array}{l}\text { SBP } 02.07 \\
\text { DBP } 02.43\end{array}$ \\
\hline Selvakumar and Raja, 2015 [12] & Control 134.34 & 131.48 & Control 90.18 & 86.96 & $\begin{array}{l}\mathrm{SBP}-02.86 \\
\mathrm{DBP}-03.22\end{array}$ \\
\hline Singh et al., 2015 [23] & $120.3 \pm 6.6$ & $118.1 \pm 6.0$ & $82.7 \pm 6.3$ & $81.5 \pm 3.6$ & $\begin{array}{l}\text { SBP }-02.20 \\
\mathrm{DBP}-01.20\end{array}$ \\
\hline Raja, 2014 [24] & $129.87 \pm 7.96$ & $128.60 \pm 7.92$ & $85.60 \pm 5.65$ & $84.33 \pm 5.51$ & $\begin{array}{l}\text { SBP }-01.27 \\
\text { DBP }-01.27\end{array}$ \\
\hline Subitha et al., 2012 [25] & $126.89 \pm 16.9$ & $122.71 \pm 14.4$ & $77.84 \pm 10.5$ & $75.82 \pm 9.46$ & $\begin{array}{l}\text { SBP }-04.18 \\
\text { DBP }-02.02\end{array}$ \\
\hline Lakshminarayanan et al., 2012 [13] & 122.40 & 120.84 & 76.81 & 76.07 & $\begin{array}{l}\text { SBP }-01.56 \\
\text { DBP }-00.74\end{array}$ \\
\hline \multicolumn{6}{|c|}{ Obese Adults $(n=40)$} \\
\hline Chaudhary et al., 2010 [10] & $128.10 \pm 4.95$ & $124.20 \pm 2.82$ & $85.00 \pm 3.27$ & $81.80 \pm 3.12$ & $\begin{array}{l}\text { SBP }-03.90 \\
\text { DBP }-03.20\end{array}$ \\
\hline Raju, 2014 [26] & $131.03 \pm 4.642$ & $127.93 \pm 4.89$ & $84.00 \pm 4.02$ & $82.33 \pm 3.88$ & $\begin{array}{l}\text { SBP }-03.10 \\
\text { DBP }-01.67\end{array}$ \\
\hline \multicolumn{6}{|c|}{ Hypertensive adults $(n=122)$} \\
\hline Jaiswal et al., 2015 [27] & $129.46 \pm 2.87$ & $124.6 \pm 1.95$ & $81.37 \pm 2.37$ & $79.86 \pm 2.56$ & $\begin{array}{l}\text { SBP }-04.86 \\
\text { DBP }-01.51\end{array}$ \\
\hline Patel and Desai, 2014 [18] & & & & & $\begin{array}{l}\text { SBP }-03.35 \\
\mathrm{DBP}-02.00\end{array}$ \\
\hline Bose and Dhanalakshmi, 2012 [28] & $145.87 \pm 5.73$ & $139.87 \pm 5.92$ & $94.80 \pm 2.86$ & $91.33 \pm 2.59$ & $\begin{array}{l}\text { SBP }-06.00 \\
\text { DBP }-03.47\end{array}$ \\
\hline Saptharishi et al., 2009 [14] & 128.6 & 123.3 & 87.4 & 81.4 & $\begin{array}{c}\text { SBP }-05.30 \\
\mathrm{DBP}-06.00 \\
\end{array}$ \\
\hline \multicolumn{6}{|c|}{ Diabetic adults $(n=239)$} \\
\hline Sadhesh and Kumar, 2014 [15] & 119.69 & 112.89 & 74.45 & 74.45 & $\begin{array}{l}\text { SBP }-06.80 \\
\text { DBP } 00.00\end{array}$ \\
\hline Ghosh and Roy, 2013 [29] & $139.66 \pm 14.38$ & $127.83 \pm 13.9$ & $80.00 \pm 5.57$ & $72.25 \pm 5.46$ & $\begin{array}{l}\text { SBP }-11.80 \\
\text { DBP }-07.75\end{array}$ \\
\hline Sanghani et al., 2013 [30] & $133.47 \pm 13.23$ & $131.20 \pm 10.36$ & $84.29 \pm 9.38$ & $83.24 \pm 9.02$ & $\begin{array}{l}\text { SBP }-02.27 \\
\text { DBP }-01.05\end{array}$ \\
\hline Tiwari et al., 2012 [17] & $131.92 \pm 18.25$ & $121.84 \pm 15.03$ & $84.76 \pm 12.12$ & $79.50 \pm 7.48$ & $\begin{array}{c}\text { SBP }-10.08 \\
\text { DBP }-05.26\end{array}$ \\
\hline Sridhar et al., 2010 [31] & $144.24 \pm 2.87$ & $135.53 \pm 3.54$ & $88.59 \pm 3.92$ & $82.82 \pm 1.07$ & $\begin{array}{c}\text { SBP }-08.71 \\
\text { DBP }-05.77\end{array}$ \\
\hline Arora et al., 2009 [32] & $132 \pm 8.5$ & $124 \pm 11.6$ & $84 \pm 5.3$ & $81 \pm 8.2$ & $\begin{array}{l}\text { SBP }-08.00 \\
\text { DBP }-03.00\end{array}$ \\
\hline Shenoy et al., 2009 [33] & $132 \pm 8.5$ & $129 \pm 11.6$ & $84 \pm 5.3$ & $83 \pm 7.4$ & $\begin{array}{l}\text { SBP }-03.00 \\
\text { DBP }-01.00\end{array}$ \\
\hline
\end{tabular}


Chaudhary et al., 2010 [10]

Dureja and Bardhan, 2014 [19]

Munieskhar, et al., 2014 [20]

Golda and Margaret, 2013 [11]

Harsoda and Purohit, 2013 [21]

Hulke et al., 2012 [16]

Karadkhedkar and Somwanshi, 2015 [22]

Selvakumar and Raja, 2015 [12]

Singh et al., 2015 [23]

Raja, 2014 [24]

Subitha et al., 2012 [25]

Lakshminarayanan et al., 2012 [13]

Raju, 2014 [26]

\section{Healthy Indians}

Jaiswal et al., 2015 [27]

Patel and Desai, 2014 [18]

Bose and Dhanalakshmi, 2012 [28]

Saptharishi et al., 2009 [14]

Hypertensive Indians

Sadhesh and Kumar, 2014 [15]

Ghosh and Roy, 2013 [29]

Sanghani et al., 2013 [30]

Tiwari et al., 2012 [17]

Sridhar et al., 2010 [31]

Arora et al., 2009 [32]

Shenoy et al., 2009 [33]

Diabetic Indians

Overall Indians

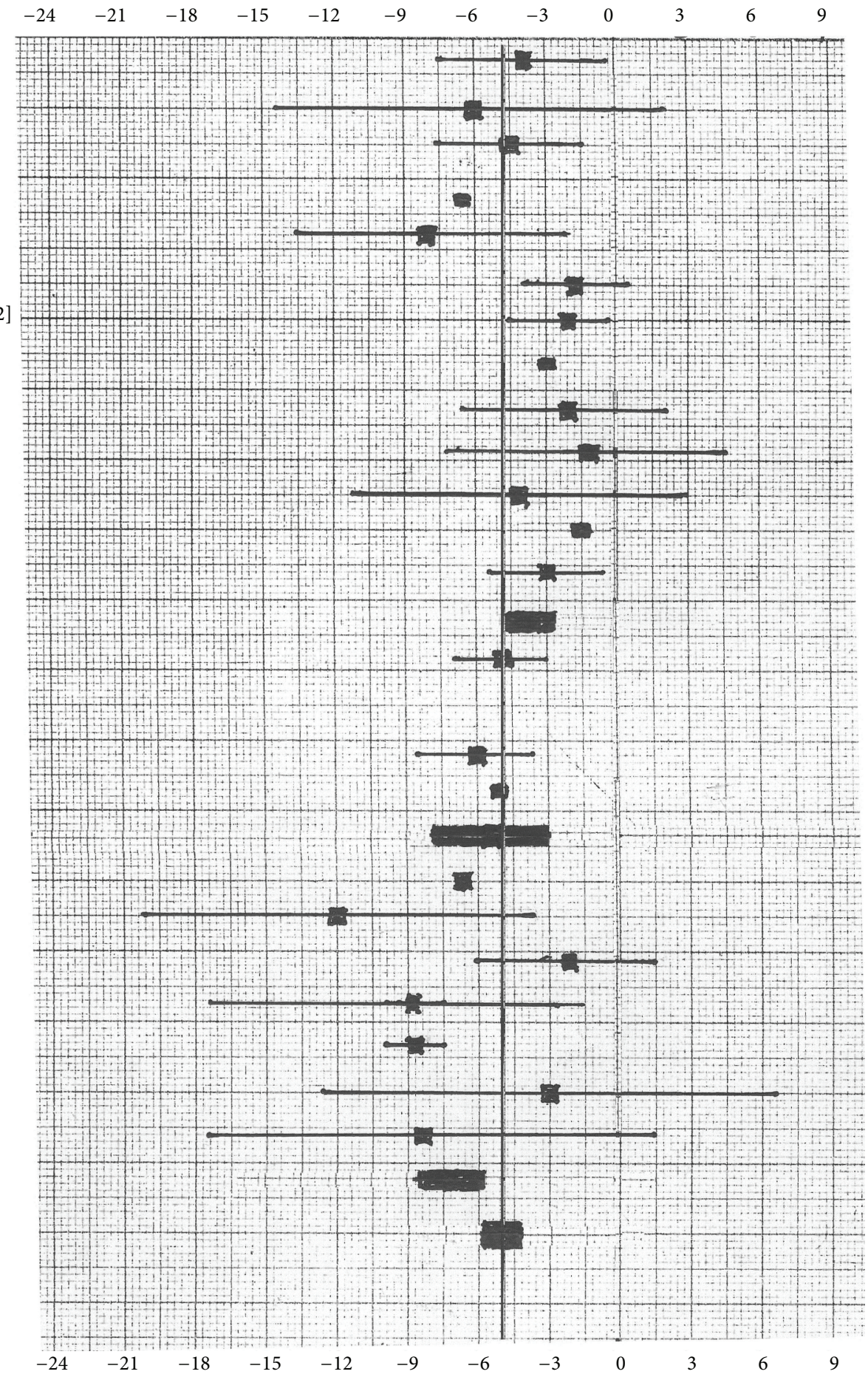

FIGURE 1: Summary of aerobic training on SBP (mean difference with 95\% CI) in Indians. Bold vertical line is meta-analysis mean $(n=23)$.

Hypertension is a growing problem in India with every third to fifth Indian as hypertensive [2,37, 38]. Approximately $10 \%$ of death in India was attributable to high blood pressure [39]. It is the third leading risk factor for disease burden in both developed and developing nations worldwide [40]. According to SEEK study, ischemic heart disease, stroke, and peripheral vascular diseases are significantly higher in hypertensive Indian population than in control [41]. In a recent meta-analysis of 18 prospective cohorts, compared to normotension, prehypertension elevated the risk of cardiovascular disease (CVD) by 1.55 (relative risk, RR), coronary heart disease (CHD) by 1.50, and stroke by 1.71 [4]. It is one of the most common modifiable risk factors in CVD. Mean reduction of $3.0 \mathrm{mmHg}$ in SBP could reduce mortality from CHD by $6 \%$ and from stroke by $9 \%$ [42]. Another study found that rise of SBP by $3.0 \mathrm{mmHg}$ and DBP by $2.3 \mathrm{mmHg}$ 
Chaudhary et al., 2010 [10]

Dureja and Bardhan, 2014 [19]

Munieskhar, et al., 2014 [20]

Golda and Margaret, 2013 [11]

Harsoda and Purohit, 2013 [21]

Hulke et al., 2012 [16]

Karadkhedkar and Somwanshi, 2015 [22]

Selvakumar and Raja, 2015 [12]

Singh et al., 2015 [23]

Raja, 2014 [24]

Subitha et al., 2012 [25]

Lakshminarayanan et al., 2012 [13]

Raju, 2014 [26]

Healthy Indians

Jaiswal et al., 2015 [27]

Patel and Desai, 2014 [18]

Bose and Dhanalakshmi, 2012 [28]

Saptharishi et al., 2009 [14]

\section{Hypertensive Indians}

Sadhesh and Kumar, 2014 [15]

Ghosh and Roy, 2013 [29]

Sanghani et al., 2013 [30]

Tiwari et al., 2012 [17]

Sridhar et al., 2010 [31]

Arora et al., 2009 [32]

Shenoy et al., 2009 [33]

Diabetic Indians

Overall Indians

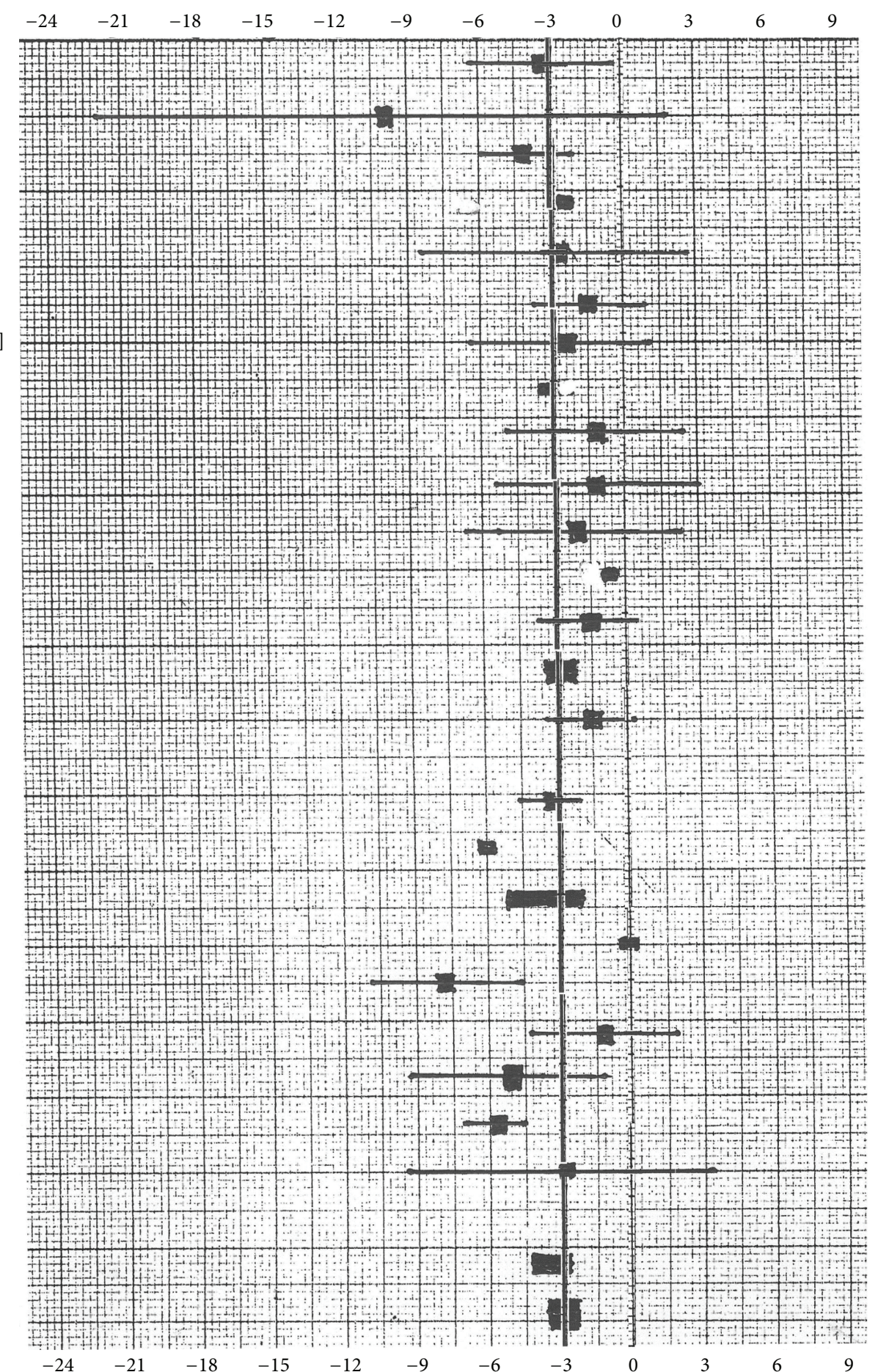

FIGURE 2: Summary of aerobic training on DBP (mean difference with 95\% CI) in Indians. Bold vertical line is meta-analysis mean $(n=23)$.

would result in estimated $12 \%$ increased risk for $\mathrm{CHD}$ and $24 \%$ increased risk for stroke [43].

There are some limitations observed in this review. We used improvement in BP using after minus before values, except one study [12], and one study used MD instead of blood pressure values [18]. Sample size, training duration, session duration, and frequency of training are varied between studies which may underestimate or overestimate our interpretations in results and we do not use any statistical tests to see their association with BP lowering effect. 


\section{Conclusion}

Aerobic training of 4 -week duration would reduce BP to a clinically significant level in Indian population. This reduction is more pronounced in clinical conditions like hypertension and diabetes. So this type of training should be used as primary prevention in high risk population and as secondary prevention in hypertension, diabetes, and so forth.

\section{Competing Interests}

The authors declare that there are no competing interests regarding the publication of this paper.

\section{References}

[1] V. Patel, S. Chatterji, D. Chisholm et al., "Chronic diseases and injuries in India," The Lancet, vol. 377, no. 9763, pp. 413-428, 2011.

[2] R. Anchala, N. K. Kannuri, H. Pant et al., "Hypertension in India: a systematic review and meta-analysis of prevalence, awareness, and control of hypertension," Journal of Hypertension, vol. 32, no. 6, pp. 1170-1177, 2014.

[3] R. Gupta, "Convergence in urban-rural prevalence of hypertension in India," Journal of Human Hypertension, vol. 30, no. 2, pp. 79-82, 2016.

[4] Y. Huang, S. Wang, X. Cai et al., "Prehypertension and incidence of cardiovascular disease: a meta-analysis," BMC Medicine, vol. 11, no. 1, article 177, pp. 1-9, 2013.

[5] J. Hsia, K. L. Margolis, C. B. Eaton et al., "Prehypertension and cardiovascular disease risk in the women's health initiative," Circulation, vol. 115, no. 7, pp. 855-860, 2007.

[6] V. A. Cornelissen and N. A. Smart, "Exercise training for blood pressure: a systematic review and meta-analysis," Journal of the American Heart Association, vol. 2, no. 1, Article ID e004473, 2013.

[7] K. Ueshima, K. Ishikawa-Takata, T. Yorifuji et al., "Physical activity and mortality risk in the Japanese elderly. A cohort study," American Journal of Preventive Medicine, vol. 38, no. 4, pp. 410-418, 2010.

[8] M. Reiner, C. Niermann, D. Jekauc, and A. Woll, "Long-term health benefits of physical activity-a systematic review of longitudinal studies," BMC Public Health, vol. 13, no. 1, article 813, pp. 1-9, 2013.

[9] P. K. Changela, "A study to compare the effect of aerobic and resistance training on cardiovascular fitness in young obese sedentary females," International Journal of Scientific and Research Publications, vol. 3, no. 2, 9 pages, 2013.

[10] S. Chaudhary, M. K. Kang, and J. S. Sandhu, "The effects of aerobic versus resistance training on cardiovascular fitness in obese sedentary females," Asian Journal of Sports Medicine, vol. 1, no. 4, pp. 177-184, 2010.

[11] J. Golda and J. G. D. Margaret, "Impact of cardio-respiratory endurance training resistance training and core strength training on selected physiological variables among college athletes," Journal of Academic Sports Scholar, vol. 2, no. 12, 5 pages, 2013.

[12] S. Selvakumar and S. C. Raja, "Effects of aerobic exercise programme on different terrains on blood pressure and assertiveness," International Journal of Recent Research and Applied Studies, vol. 2, no. 13, pp. 55-58, 2015.
[13] S. Lakshminarayanan, S. M. Bala, M. Ramanujam, and G. Kannan, "Effectiveness of physical activity promotion in blood pressure and blood sugar reduction: a community-based intervention study in rural south India," Journal of Family and Community Medicine, vol. 19, no. 2, pp. 81-87, 2012.

[14] L. G. Saptharishi, M. B. Soudarssanane, D. Thiruselvakumar et al., "Community-based randomized controlled trial of nonpharmacological interventions in prevention and control of hypertension among young adults," Indian Journal of Community Medicine, vol. 34, no. 4, pp. 329-334, 2009.

[15] A. Sadhesh and G. V. Kumar, "Influence of low to moderate intense training between type 1 and type 2 diabetic," International Journal of Health, Physical Education \& Computer Science in Sports, vol. 16, pp. 68-72, 2014.

[16] S. M. Hulke, Y. P. Vaidya, and A. R. Ratta, "Effects of sixteen weeks exercise training on left ventricular dimensions and function in young athletes," National Journal of Physiology, Pharmacy \& Pharmacology, vol. 2, no. 2, pp. 152-158, 2012.

[17] S. Tiwari, S. Gehlot, S. K. Tiwari, and G. Singh, "Effect of walking (aerobic isotonic exercise) on physiological variants with special reference to Prameha (diabetes mellitus) as per Prakriti," $A Y U$, vol. 33, no. 1, pp. 44-49, 2012.

[18] H. Patel and D. Desai, "A study to evaluate the changes in blood pressure values of hypertensive patients post aerobic and progressive resistance exercise (PRE)," International Journal of Health Sciences and Research, vol. 3, no. 2, pp. 183-189, 2014.

[19] G. Dureja and S. Bardhan, "Effect of treadmill training on blood pressure among young adult boys," Education Practice and Innovation, vol. 1, no. 1, pp. 1-5, 2014.

[20] K. Munieskhar, M. V. Muralidhar, M. Venkatachalam, and D. Hemalatha, "Comparision of heart rate and blood pressure changes during walking and running before and after training in healthy adult women," International Journal of Physiotherapy and Research, vol. 2, no. 3, pp. 537-541, 2014.

[21] J. M. Harsoda and G. Purohit, "Effect of different modes of aerobic exercise on cardiorespiratory efficiency and exercise performance in sedentary males," International Journal of Basic and Applied Physiology, vol. 2, no. 1, p. 72, 2013.

[22] S. Karadkhedkar and N. D. Somwanshi, "Effect of aerobic training on $\mathrm{VO}_{2}$ max and other physiological parameters in working women," Indian Journal of Clinical Anatomy and Physiology, vol. 2, no. 2, pp. 105-107, 2015.

[23] V. Singh, P. Thakur, and B. Khandelwal, "Effectiveness of shortterm aerobic exercise program on cardiovascular risk profile in moderate risk adults: a randomized controlled pilot study," CHRISMED Journal of Health and Research, vol. 2, no. 1, pp. 3845, 2015.

[24] S. C. Raja, "Effect of yogic practices and physical exercises on strength endurance self-concept and blood pressure," International Journal of Physical Education Sports Management and Yogic Sciences, vol. 4, no. 3, pp. 7-11, 2014.

[25] L. Subitha, S. M. Bala, and M. Ramanujam, "Community based physical exercise program for the elderly in South India," National Journal of Community Medicine, vol. 3, no. 4, pp. 675-680, 2012.

[26] P. S. Raju, "Twelve weeks of aerobic dance impact on cardiovascular parameters of male obese adults," International Journal of Physical Education, Fitness \& Sports, vol. 3, no. 1, pp. 51-55, 2014.

[27] A. V. Jaiswal, A. H. Kazi, S. B. Gunjal, P. M. Tawde, A. A. Mahajan, and S. M. Khatri, "Effectiveness of interval training versus circuit training exercises on blood pressure, heart rate 
and rate of perceived exertion in individual with prehypertension," International Journal of Health Sciences and Research, vol. 5, no. 10, pp. 149-156, 2015.

[28] M. Bose and V. Dhanalakshmi, "Effect of short duration aerobic exercises on resting blood pressure and heart rate in prehypertensive and stage 1 hypertensive subjects," International Journal of Physiotherapy and Occupational Therapy, vol. 6, no. 4, pp. 191-195, 2012.

[29] S. S. Ghosh and G. S. Roy, "Effects of six month aerobic training on selected physiological variables of moderately active female NIDDM," International Journal of Movement Education and Social Science, vol. 2, no. 2, pp. 4-8, 2013.

[30] N. B. Sanghani, D. N. Parchwani, K. M. Palandurkar, A. M. Shah, and J. V. Dhanani, "Impact of lifestyle modification on glycemic control in patients with type 2 diabetes mellitus," Indian Journal of Endocrinology and Metabolism, vol. 17, no. 6, pp. 1030-1039, 2013.

[31] B. Sridhar, N. Haleagrahara, R. Bhat, A. B. Kulur, S. Avabratha, and P. Adhikary, "Increase in the heart rate variability with deep breathing in diabetic patients after 12-month exercise training," Tohoku Journal of Experimental Medicine, vol. 220, no. 2, pp. 107-113, 2010.

[32] E. Arora, S. Shenoy, and J. S. Sandhu, "Effects of resistance training on metabolic profile of adults with type 2 diabetes," Indian Journal of Medical Research, vol. 129, no. 5, pp. 515-519, 2009.

[33] S. Shenoy, E. Arora, and J. Sandhu, "Effects of progressive resistance training and aerobic exercise on type 2 diabetics in Indian population," International Journal of Diabetes \& Metabolism, vol. 17, pp. 27-30, 2009.

[34] V. A. Cornelissen and R. H. Fagard, "Effects of endurance training on blood pressure, blood pressure-regulating mechanisms, and cardiovascular risk factors," Hypertension, vol. 46, no. 4, pp. 667-675, 2005.

[35] S. P. Whelton, A. Chin, X. Xin, and J. He, "Effect of aerobic exercise on blood pressure: a meta-analysis of randomized, controlled trials," Annals of Internal Medicine, vol. 136, no. 7, pp. 493-503, 2002.

[36] J. A. Halbert, C. A. Silagy, P. Finucane, R. T. Withers, P. A. Hamdorf, and G. R. Andrews, "The effectiveness of exercise training in lowering blood pressure: a meta-analysis of randomised controlled trials of 4 weeks or longer," Journal of Human Hypertension, vol. 11, no. 10, pp. 641-649, 1997.

[37] T. Midha, B. Nath, R. Kumari, Y. K. Rao, and U. Pandey, "Prevalence of hypertension in India: a meta-analysis," World Journal of Meta-Analysis, vol. 1, no. 2, pp. 83-89, 2013.

[38] P. Devi, M. Rao, A. Sigamani et al., "Prevalence, risk factors and awareness of hypertension in India: a systematic review," Journal of Human Hypertension, vol. 27, no. 5, pp. 281-287, 2013.

[39] V. Patel, S. Chatterji, D. Chisholm et al., "Chronic diseases and injuries in India," The Lancet, vol. 377, no. 9763, pp. 413-428, 2011.

[40] M. Ezzati, A. D. Lopez, A. Rodgers, S. Vander Hoorn, and C. J. L. Murray, "Selected major risk factors and global and regional burden of disease. Comparative risk assessment collaborating Group," The Lancet, vol. 360, no. 9343, pp. 1347-1360, 2002.

[41] Y. M. K. Farag, B. V. Mittal, S. R. Keithi-Reddy et al., "Burden and predictors of hypertension in India: results of SEEK (Screening and Early Evaluation of Kidney Disease) study," BMC Nephrology, vol. 15, article 42, 2014.
[42] J. Stamler, G. Rose, R. Stamler, P. Elliott, A. Dyer, and M. Marmot, "INTERSALT study findings. Public health and medical care implications," Hypertension, vol. 14, no. 5, pp. 570-577, 1989.

[43] P. Poirier, T. D. Giles, G. A. Bray et al., "Obesity and cardiovascular disease: pathophysiology, evaluation, and effect of weight loss: an update of the 1997 American Heart Association Scientific Statement on Obesity and Heart Disease from the Obesity Committee of the Council on Nutrition, Physical Activity, and Metabolism," Circulation, vol. 113, no. 6, pp. 898-918, 2006. 


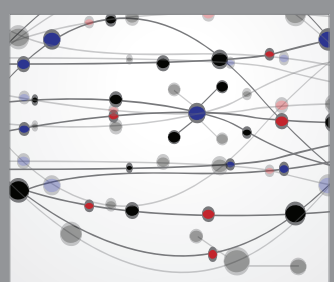

The Scientific World Journal
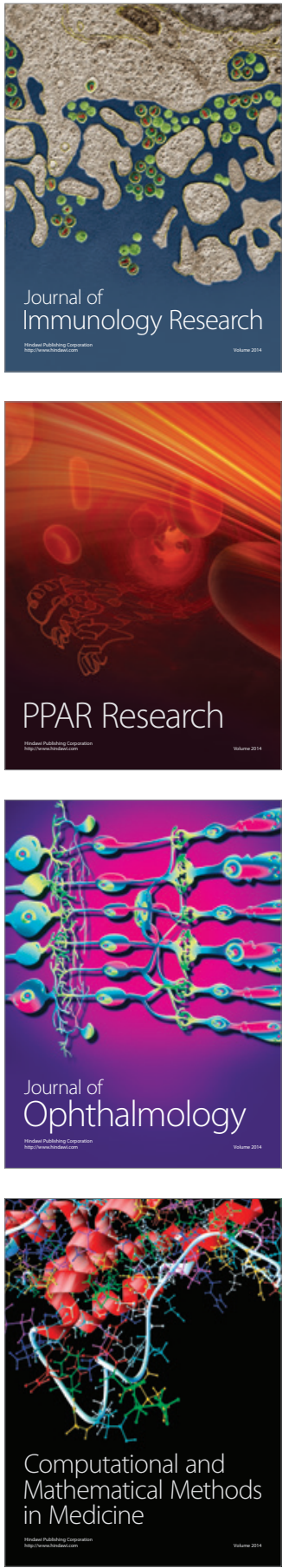

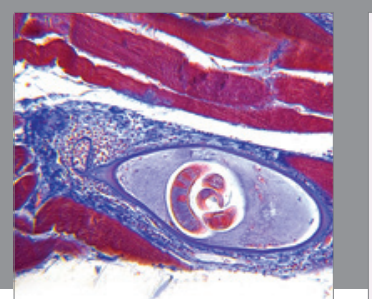

Gastroenterology Research and Practice

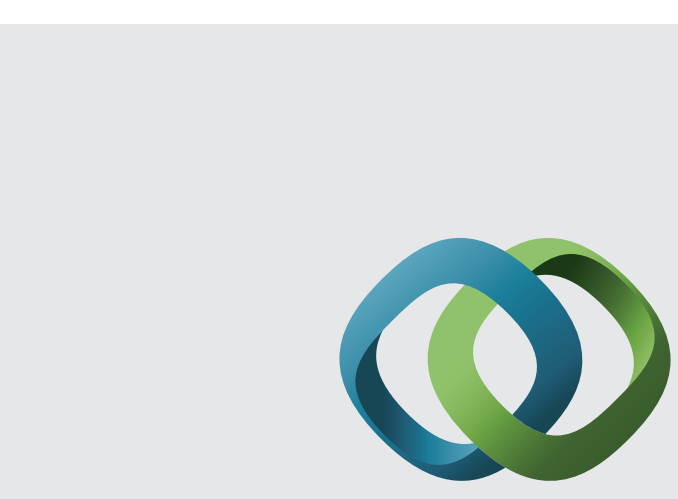

\section{Hindawi}

Submit your manuscripts at

http://www.hindawi.com
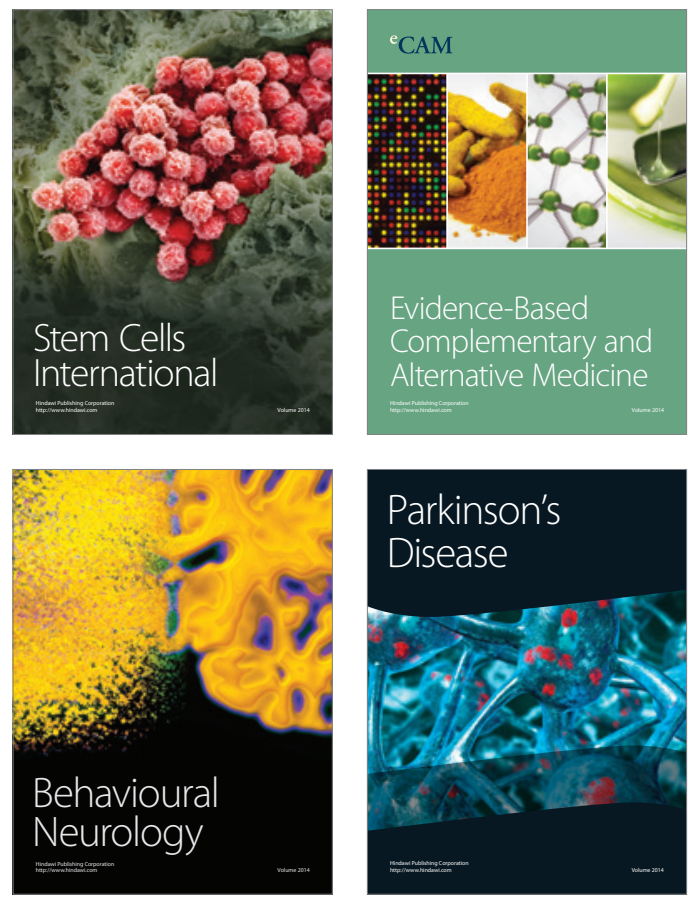
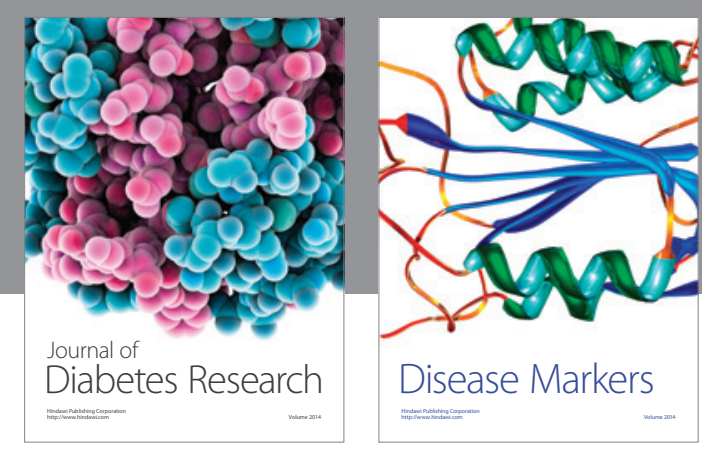

Disease Markers
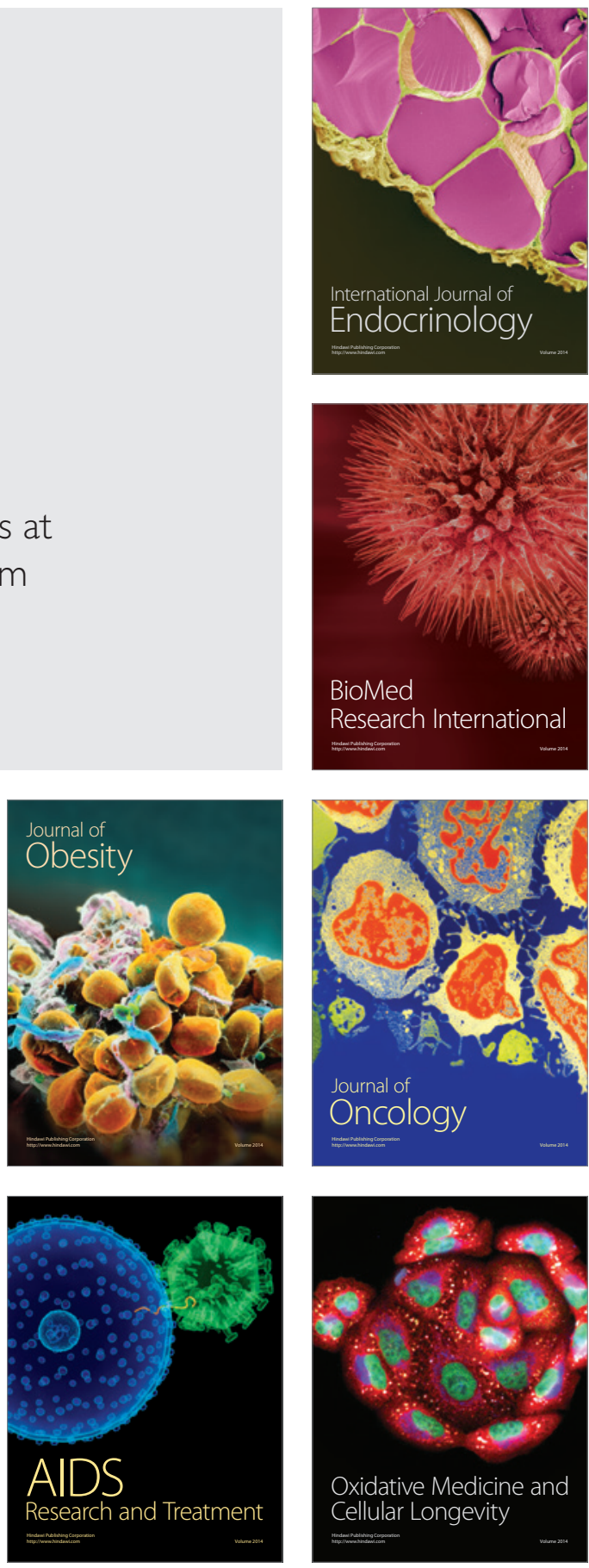